در اسة مقارنة في الاستجابة الانفعالية بين لاعبي فعاليات

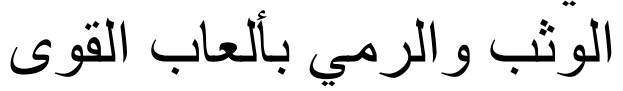

$$
\text { م.م نواف عويد عبود العبيدي }
$$

جامعة الموصل / كلية التربية الرياضية عوديلة

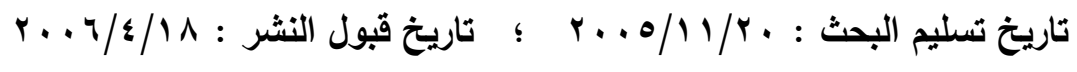

هدف البحث إلى التعرف على الفروق في درجة الاستجابة الانفعالية بين فعاليات

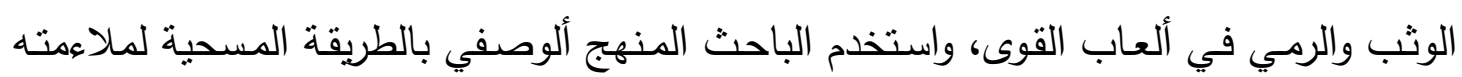

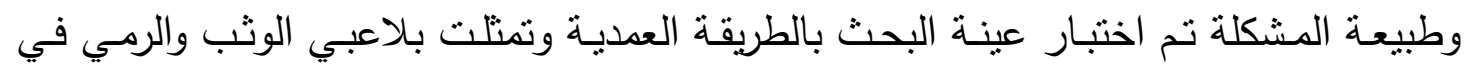

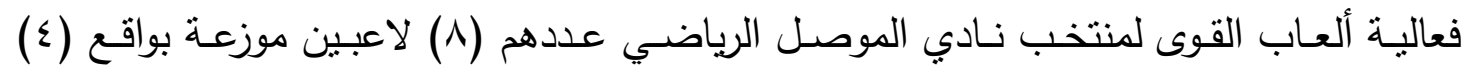

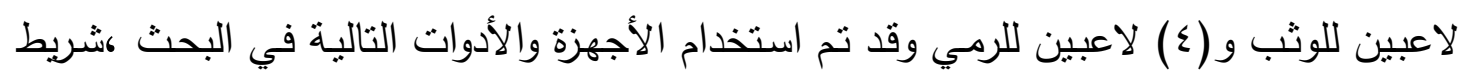

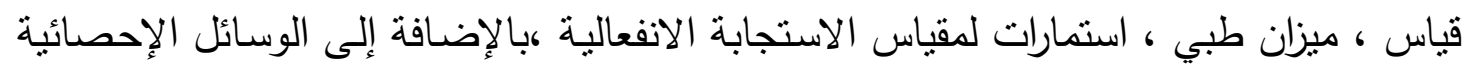

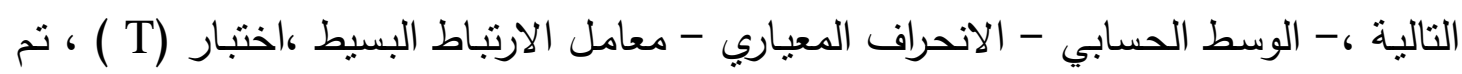
تحليل جميع البيانات إحصائيا باستخدام الحاسوب الآلي باستخدام نظام (Excel) وتحت إنشراف الإن متخصص في هذا المجال . واستنتج الباحث ماياتي : - هناك تباين في الاستجابة الانفعالية بين لاعبي الاعبي الوثب ولاعبي الرمي.

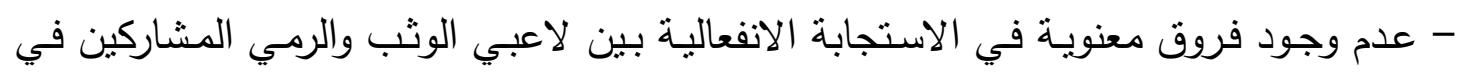
منافسات ألعاب القوى.

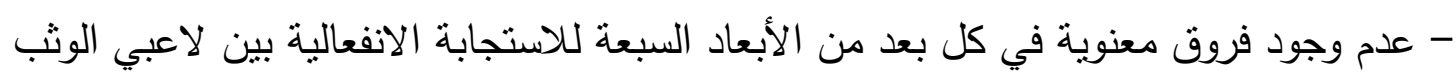

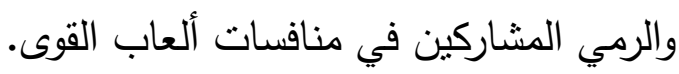
وأوصى بما يأتي : - التأكبد على تصاعد درجة الإعداد النفسي وفقا لتصاعد حساسية وأهمية المباريات والمنافسات التي يخوضها اللاعبون.

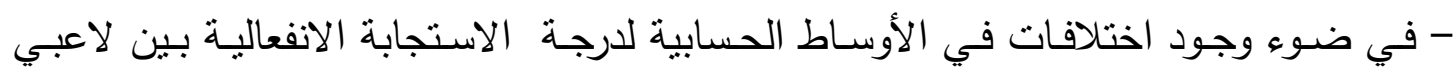

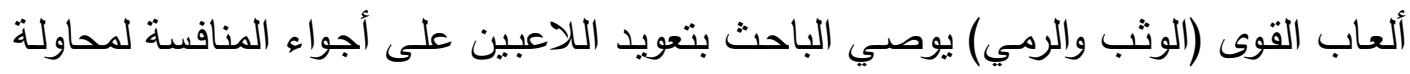

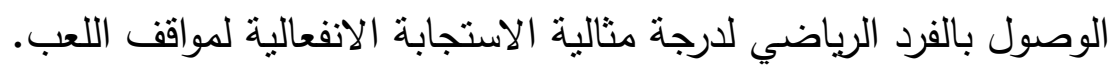

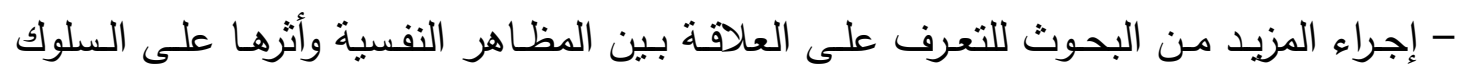
والاستجابات في مواقف المنافسة لعينات اكبر وفي الالعاب الفردية والجماعية. 


\title{
Emotional response between players of jumping \& throwing activities in track and field a comparative study
}

\author{
Nawaf U'waed Al-Ubaedy \\ University of Mousl - College of Sport Education
}

Abstract:

The research aimed at recognizing the differences in emotional between throwing and jumping activities in track and field. the researcher has used the descriptive method with a surwy teaching as it is convenient with the nature of the problem . research sample has been selected on the basis of an intentional method; represented by players of jumping \& throwing activities in track and field belong to the team of mosul sport club . the sample has consisted of ( 8 ) players distributed in the amount of ( 4 ) players for jumping and ( 4 ) players for throwing . the following devices and tools were used in the research :

Measurement strip and forms for measuring emotional response in addition to the following statistical means :

Arithmaticmean, normative deiation, simple correlation coefficient a $\mathrm{t}$ test . all data have been analyzed statistcally by means of computer excel program ; under the supervision of a specialist in this field .

The researcher has concluded the following

- there had been a difference in emotional response between the players of jumping and the players of throwing .

- no significant differences shown in emotional response between the players of jumping and throwing who participated in track and field comptitions.

- no significant differences found in each of the seventh dimensions of emotional response between players of jumping and throwing who took part in track \& field competitions .

The researcher has recomendded the following :

- confirm the escalation of psychological preparation according to the increase of the sansitivity and significance of comptitions and matches played by the players .

- in the light of differences in arithmetic means for the degree of emotional response between players of jumping and throwing in track and field . the researcher recommends that players should be accustomed to the atmospheres of the contests in an attempt to have an athlete reaches to an optimum degree of emotional response in game attitudes .

- perform further researches to recognize the relation between psychological manifestations and thier impact on behavior and responses in contests for larger samples and in single and collective game . 


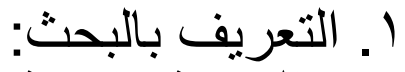 \\ ا - المقدمة و الهمية البحث:}

تقاس مكانة الامم بمدى عطائها للإنسانية ، لان مهمة الإنة بناء الإنسان هي أفضل رسالة

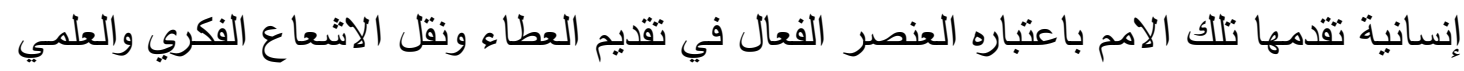

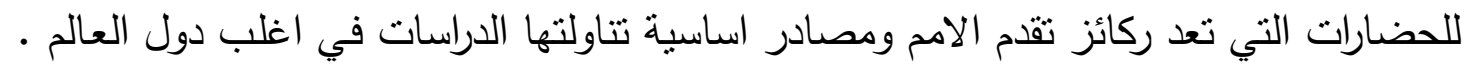

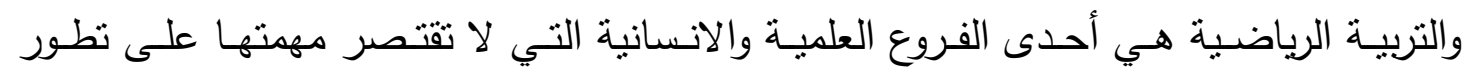

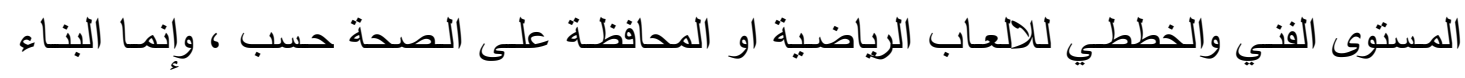

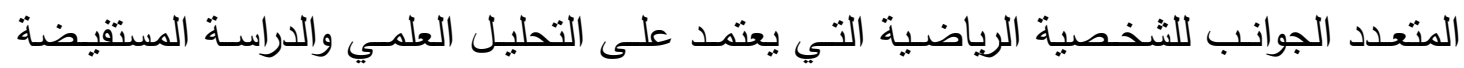

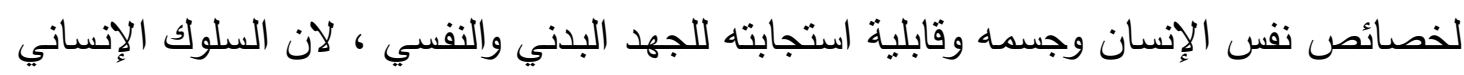

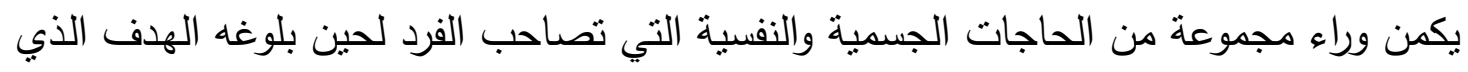

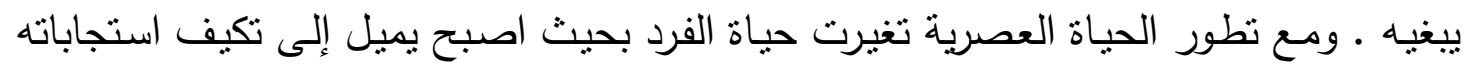

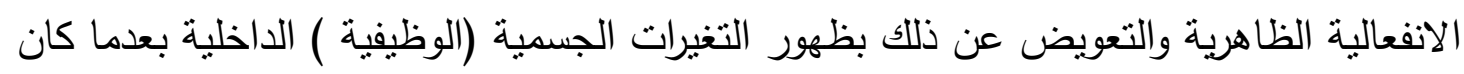

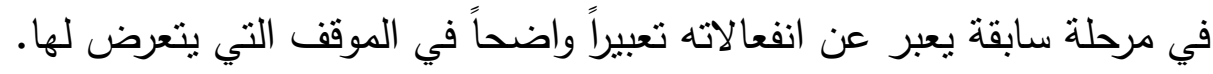

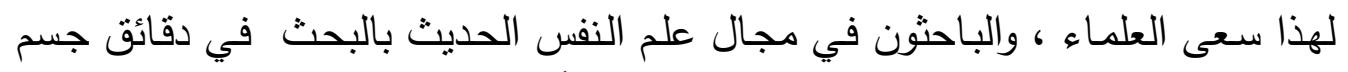

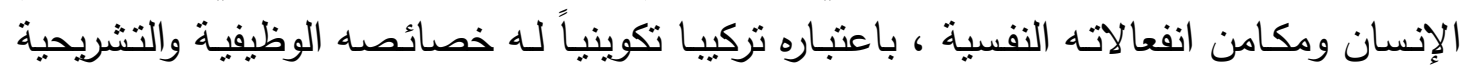

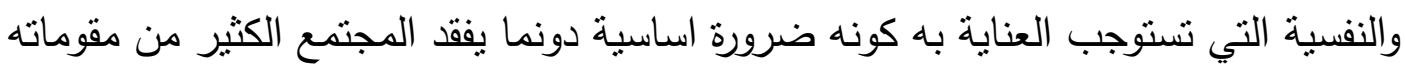

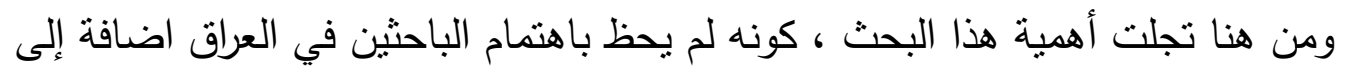

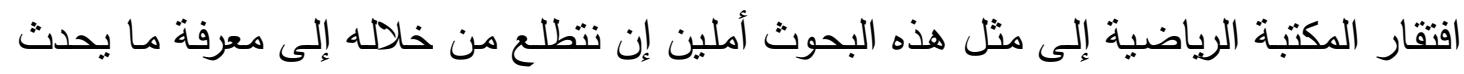

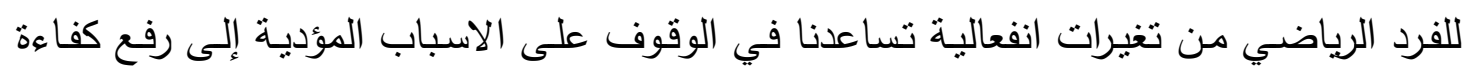

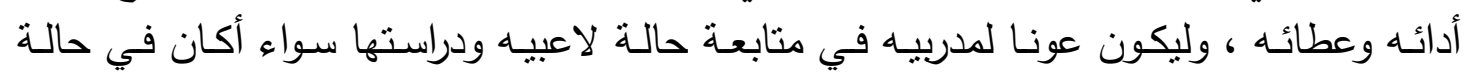

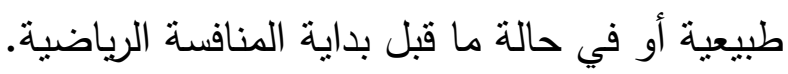

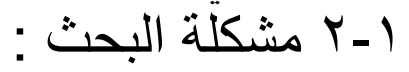

يعد إنباع الأساليب العلمية في تدريب الرياضي المتواصل من المؤشرات الدالة على تقدم

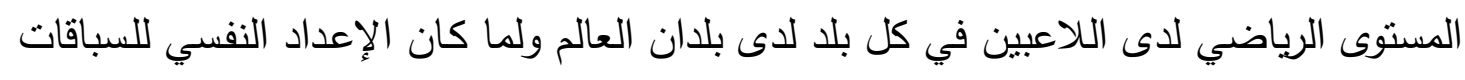

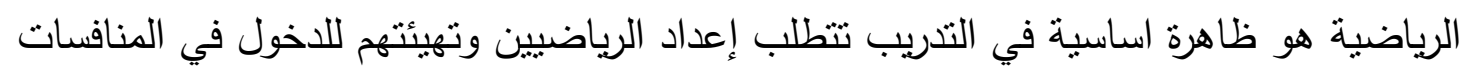

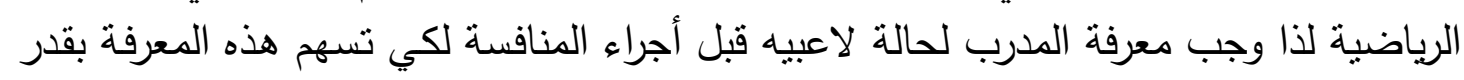

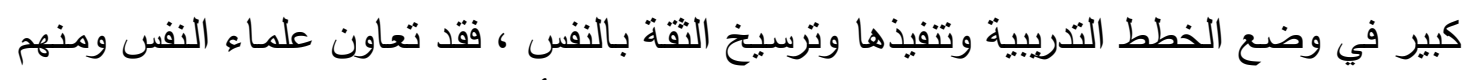

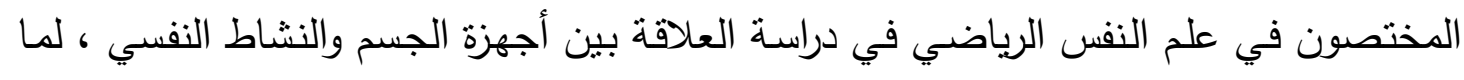

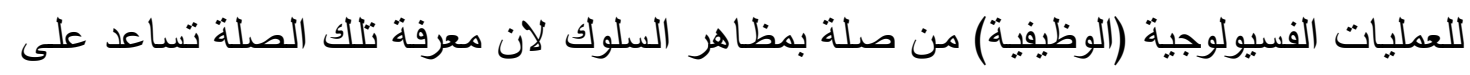

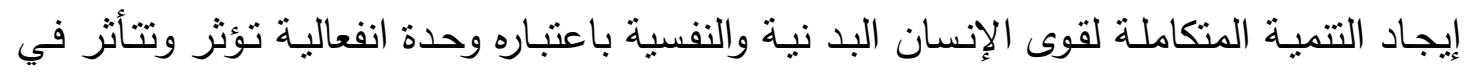

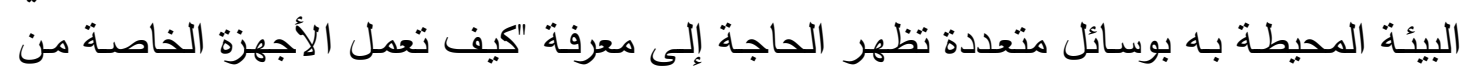

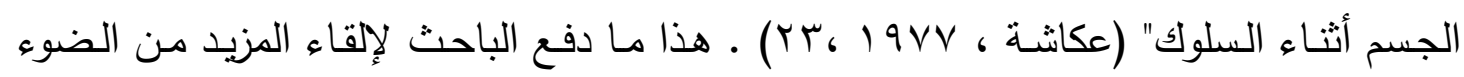

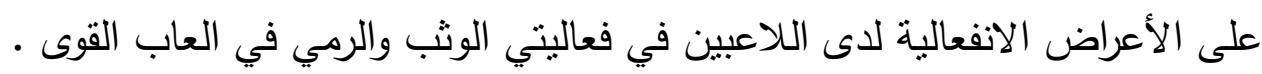




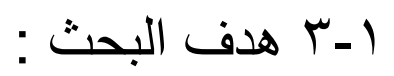

- التعرف على الفروق في الاستجابة الانفعالية بين فعاليات الوثب والرمي في العاب القوى

$$
\text { 1 - ع فرض البحث }
$$

- لا توجد فروق معنوية في درجة الاستجابة الانفعالية بين فعاليتي الوثب والرمي في القوى.

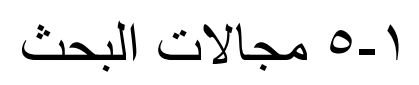

- المجال البشري : عدد من لاعبي الوثب والرمي في العاب القوى البالغ عددهم(^) لاعبين.

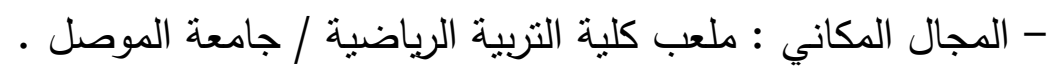

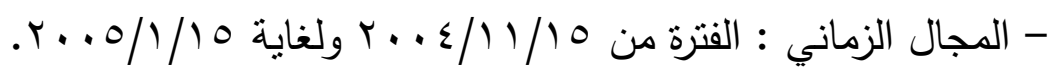

\section{1-7 تحديد المصطلحات}

إن المصطلحات الأساسية في هذا البحث التي تستوجب الإثارة إليها كما يراها الباحث

الاستجابة الانفعالية : هي رد فعل الفرد لحالة توتر تصحبها تغيرات فسيولوجية داخلية ومظاهر

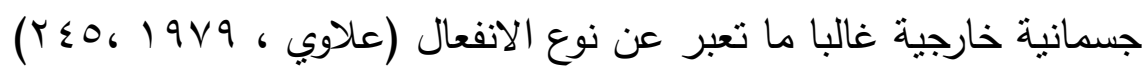
مكونات الاستجابة الانفعالية :

- الإصرار : الثعور بان اللاعب يستطيع إن يفعل في مبارياته شيئًا ما يحدث تغيراً

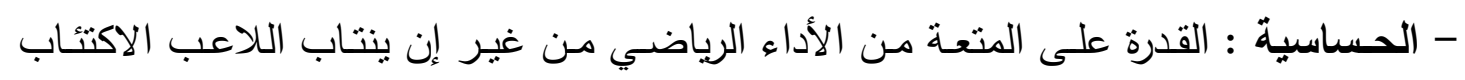

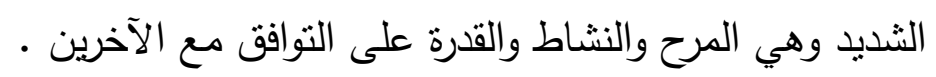

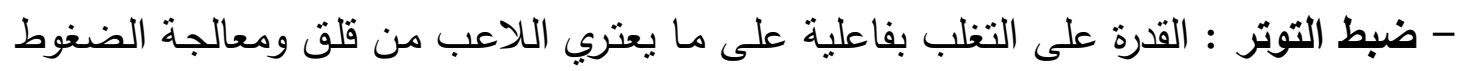
والانفعالات القوية بطريقة ايجابية .

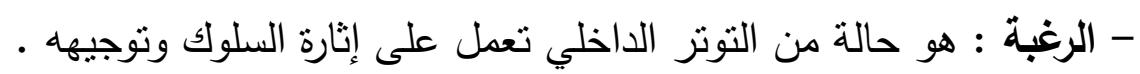

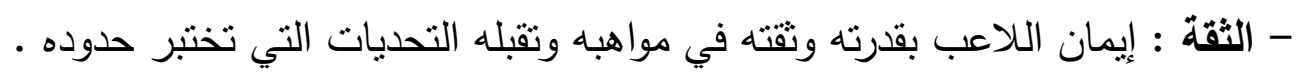

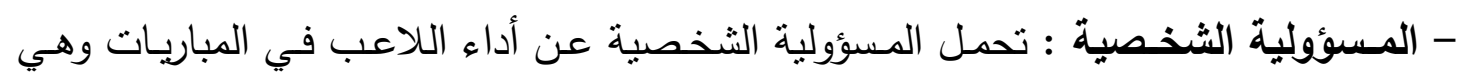

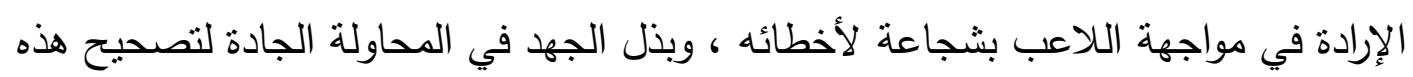

$$
\text { الأخطاء. }
$$

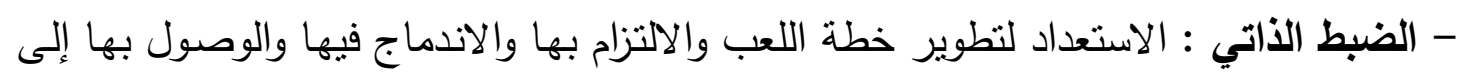

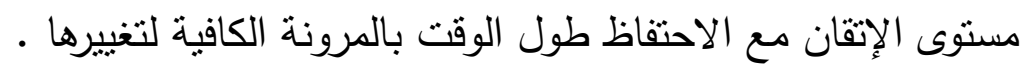

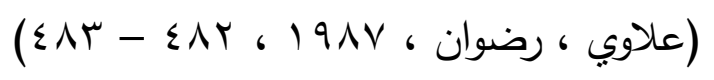

\section{$r \cdot V$}


Y - الدر اسات النظرية و الدر اسات المشابهة :

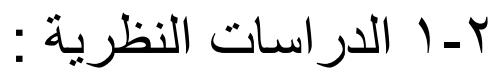

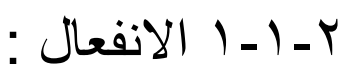

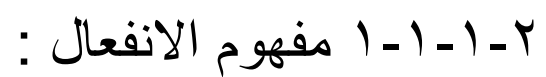

ترتبط الانفعالات بالنشاط الرياضي الممارس ارتباطاً وثيقا سواء في حالة التدريب أو في

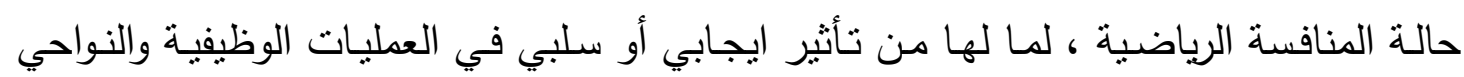

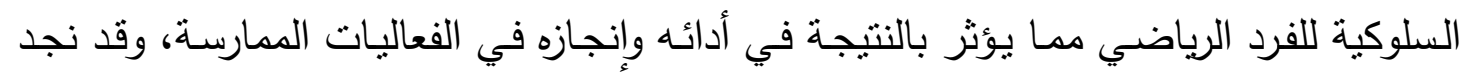

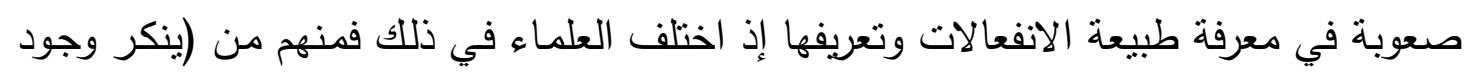

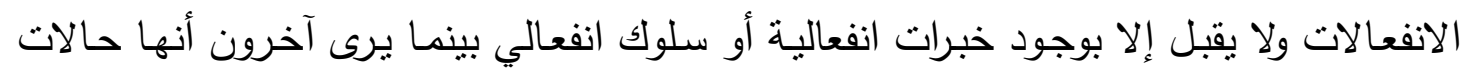

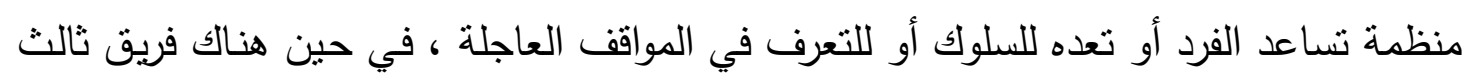

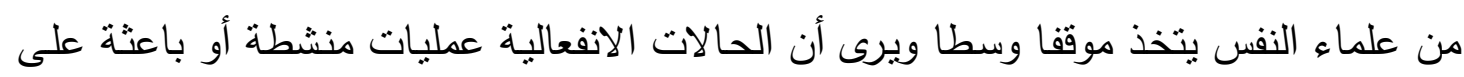

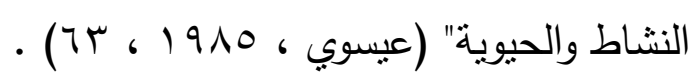

وعلى ضوء ما تقدم سنذكر أهم ما جاء به العلماء والباحثون في علم النفس من تعريفات

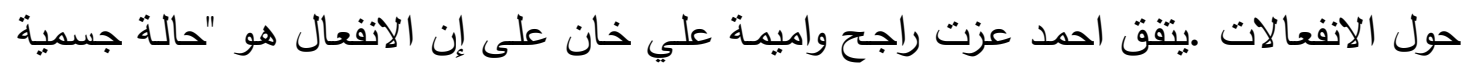

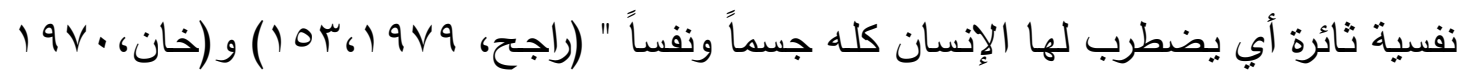
- (IT)،

إما جورج ميلر فيقول انه " عبارة عن أي خبرة ذات شعور قوي ، وغالباً ما يصاحب هذه

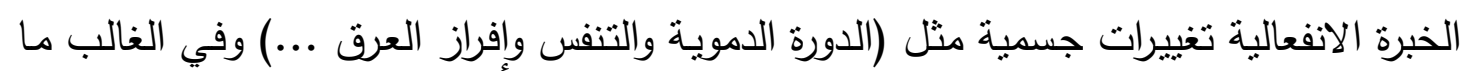
تصاحب أيضا بأفعال قهرية عنيفة أو كثيفة اوشديدة أو حادة .

(7) (بيسوي ، 1910)

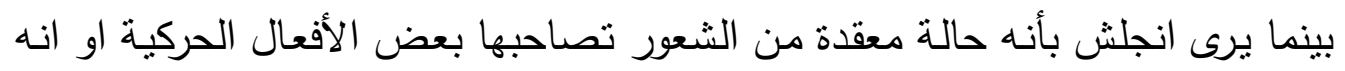

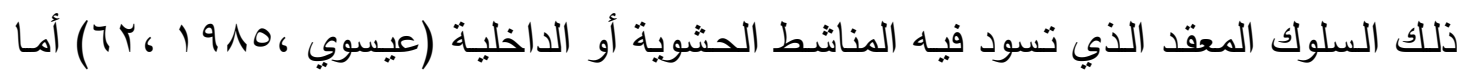
لندال دافيدوف فيذهب إلى انه "حالات داخلية تتصف بجوانب معرفيـة خاصـة ، واحساسات

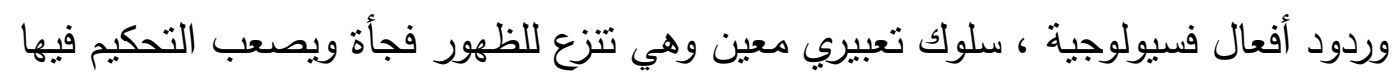

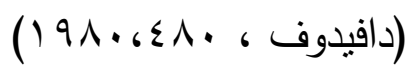

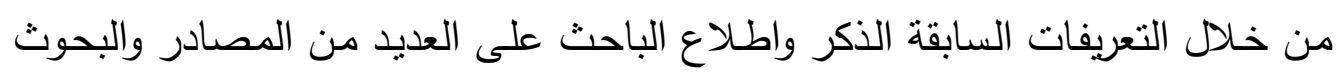

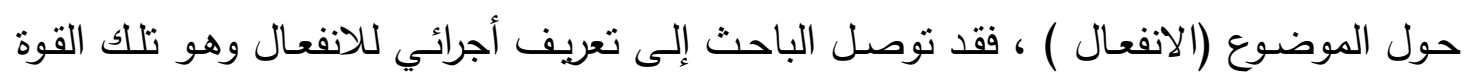

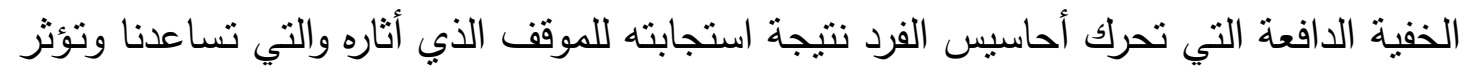
في مستوى أدائه . 


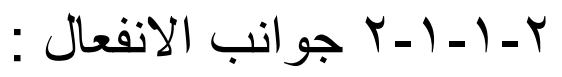

للانفعال جوانب عديدة يمكن ان تظهر على الفرد بشكل او بأخر ، وتؤثر في سلوكه ،

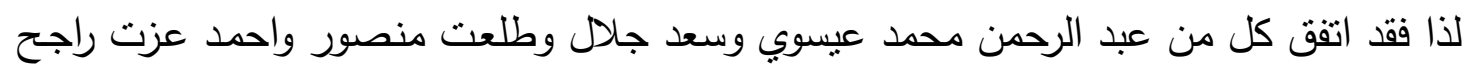

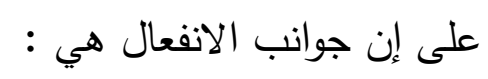

ا . جانب شعوري ذاتي يمكن إن يخبرنا به الفرد عن طريق أجابته في التقرير اللفظي الذي يدلي

$$
\text { به في المواقف التي يتعرض لها. }
$$

r. جانب سلوكي خارجي : هو كل ما يصدر عن الفرد من تغييرات لغوية او حركات جسمية وغيرها من الدلائل الظاهرية الأخرى التي نستطيع من خلالهها الحكم على الانفعال ظاهريا

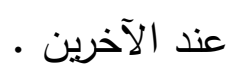

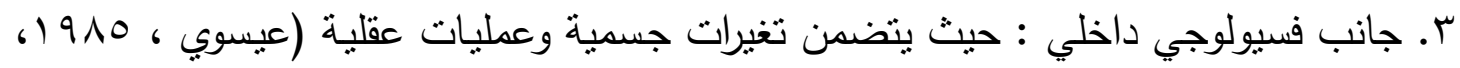

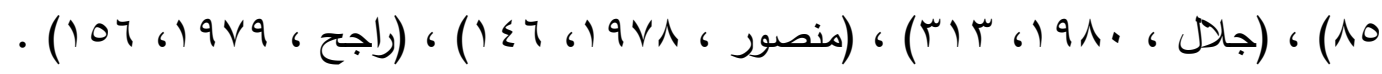

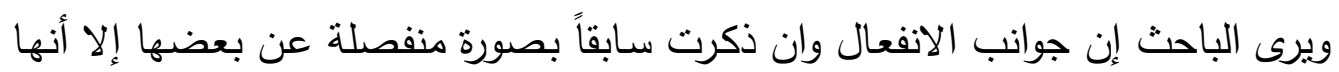

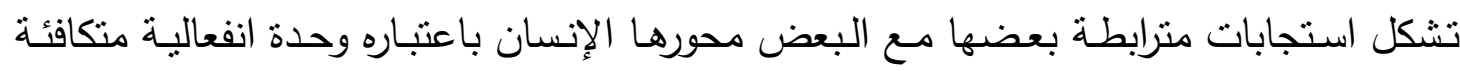

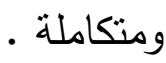

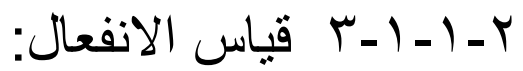

يتفق كل من (لندال دافيدوف) و (ارنوف ويتج ) ، على ان قياس الانفعال يتم عن طريق

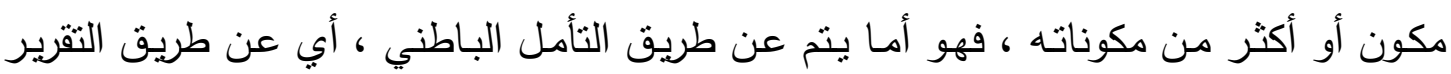

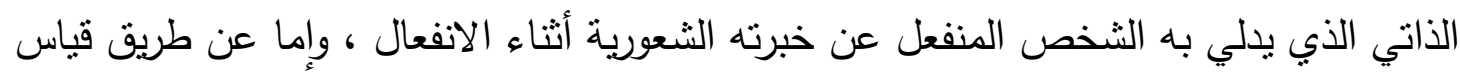
المتغيرات الفسيولوجية الداخلية ، حيث براقب الباحثون ردود أفعال الجسم المصاحبة للانفعال

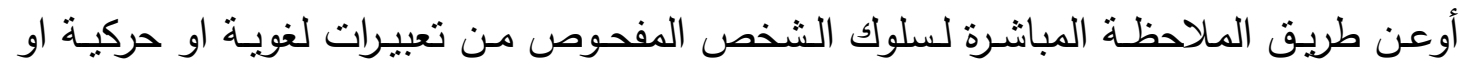

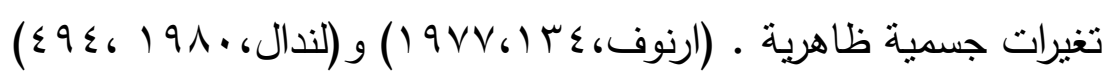
وقد ذكر العديد من الباحثين ان طريقة الحكم على نوع الانفعال يجب اندان تكون دمج بين

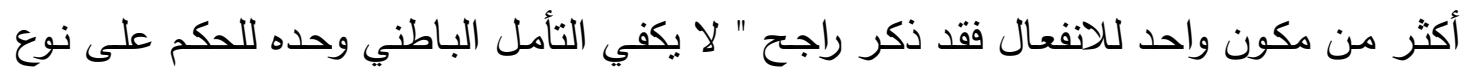
الانفعال ، وذلك لصعوبة تعبير المنفعل عن خبرته الثعورية أثناء الانفعال ، لكنه يكون ذا قيمة التاني

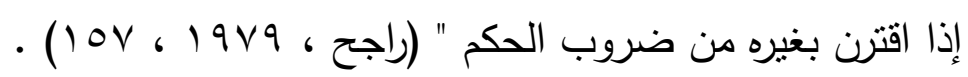

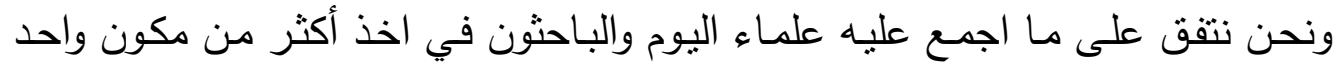

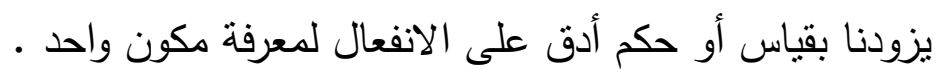

\section{Y - ا ـ ـ ـ المظاهر الفسيولوجية المصاحبة للانفعال}


يمكن تلخيص بعض التغيرات الفسيولوجية المرتبطة بالانفعالات فيما يأتي :

ץ-1-1- צ-

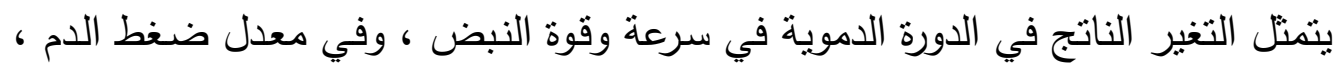

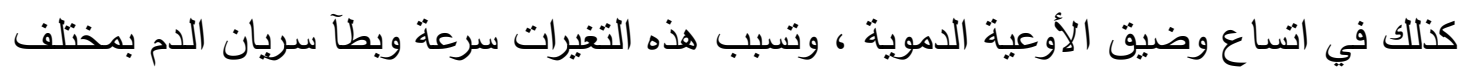

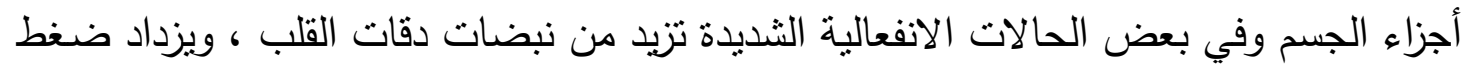

r-1-1-

ترتبط الانفعالات بالنشاط الزائد في عمل العضلات وكذلك في ارتفاع في درجة الصوت

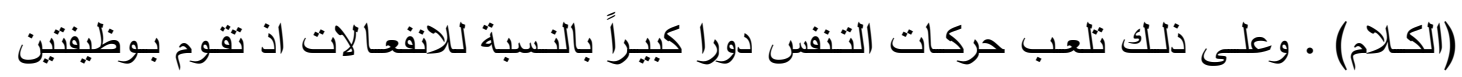
هامتين هما :

- تقوية عملية تبادل الغازات وبذلك تضمن للعمل العضلي الزائد ما يحتاجه من الأوكسجين .

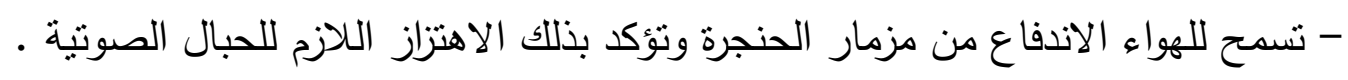

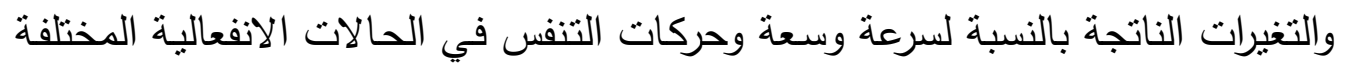

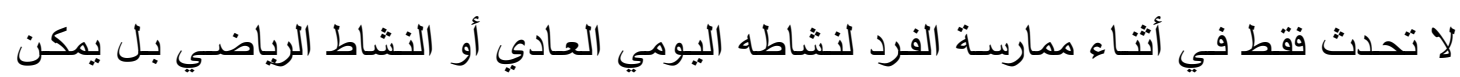

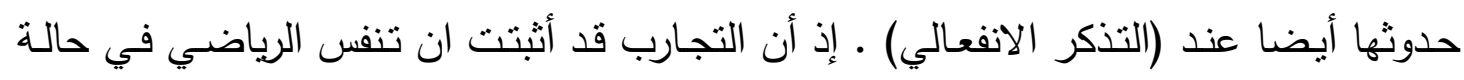
تذكره لبعض التمرينات البدنية العنيفة وخاصة تلك التي تتسم بالأهمية تأخذ نفس مظاهر التهاب عملية

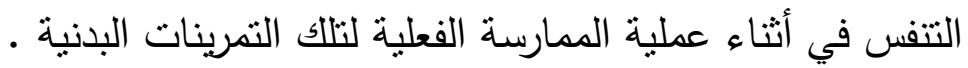

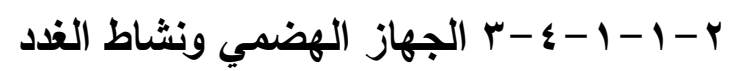

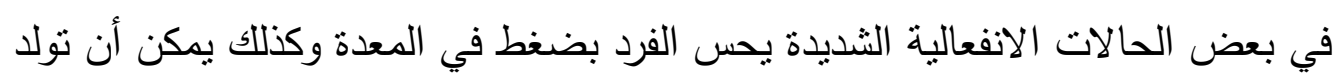

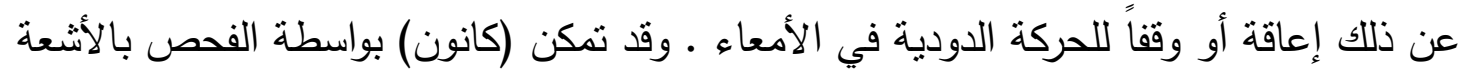
من ملاحظة نوقف الحركة الدودية في حالة الخوف ـ كما يمكن ملاحظة تغيرات مختلفة بالنسبة الأبعاه لافرازات العصير الهضمي. فتجارب (بافلوف) اثبت ان تتاول الطعام الثهي يصاحبه افرازات

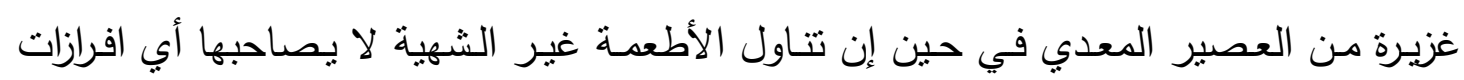
وكذلك في حالة الخوف يمكن ملاحظة نقط إفراز العصير المعدي كذلك افرازات اللعاب.

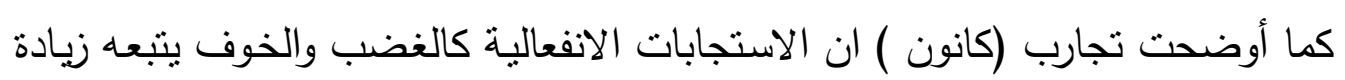

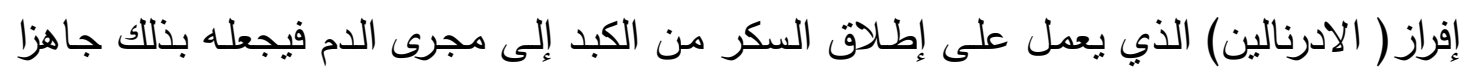


باستخدامه في إنتاج الطاقة ـ كما انه يمكن سهولة ملاحظة بعض الافرازات الخارجية من غدد في مختلف الحالات الانفعالية كالدموع والعرق وغيرها. من كل ما تقدم نجد ان العمليات الانفعالية تحتوي على الكثير من التغيرات التي تشملها كل الوظائف العضوية ـ ويرجع الفضل الى العالم (كانون) الذي أوضـح الدور الايجابي الهام

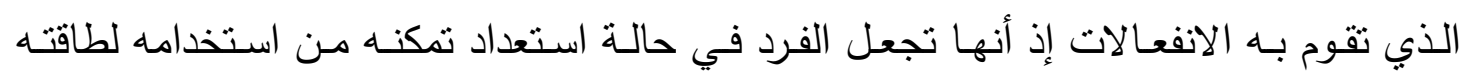
لأقصى درجة وذلك لامكان تحقيق عوامل تكيف الفرد مع البيئة . والجهاز العصبي الذاتي هـ الذي يقوم بعمليـة تتظيم التغيـرات العديدة في وظـائف الأعضاء الجسمية الداخليـة والتي يمكن ملاحظتها في الحالات الانفعاليـة الداخليـة ـ اذ يقوم الجهاز العصبي الذاتي (الاتونومي) بزيادة نشاط الأعضاء الداخلية والعمل على خفضها كنشاط القلب والرئتين والأوعية الدموية وغدد الإقرازات الداخلية والأمعاء والمعدة وغيرها.

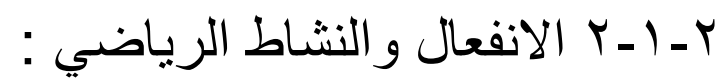

ترتبط الأنشطة الرياضية ارتباطا وثثقا بالاففعال نظرا لارتباطها بالتتافس الرياضي ، ذلك

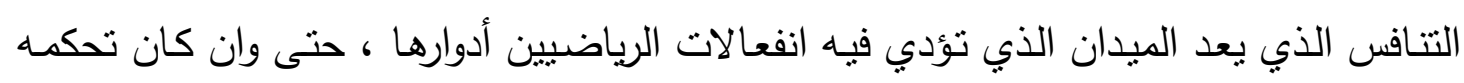
القوانين والأنظمة الرياضية التي وضعت من اجلها المنافسات ـ حيث يرافق الرياضي في هذه المنافسات الكثير من المشاكل الفنية وغير الفنية التي تشكل بمجموعها ضغطا نفسياً في هيئة انفعال تنعكس آثاره على السلوك الرياضـي وأدائه في أثناء المباريات ، فان كان مستعدا وله القدرة في السيطرة على نفسه فهذا يعني ان الانفعال ذو تأثير ايجابي في مواصلة النشاط وفي تحمل الرياضي وتمكنه من بذل الطاقة لمدة أطول. اما إذا كان الانفعال ذا تأثير سلبي فتظهر على الرياضي حالات الخوف والقلق وفقدان التقة بالنفس مما يعيق عمله عند التركيز من اجل حل الواجبات المطلوب انجازها ـ وهنا يكون الضغط النفسي والذي يفعل مفعوله في الملعب اخطر من اللاعب المنافس ، وعليه وجب إعداد الرياضي إعداد جيدا بحيث "يكون قبل المباراة في حالة انفعالية متهيجة وان تكون هذه الحالة ليست قوية ولا ضعيفة ومن المستحسن ان يكون مستوى التهيج مناسبا لشروط ومتطلبات النشاط

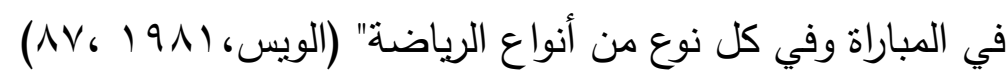

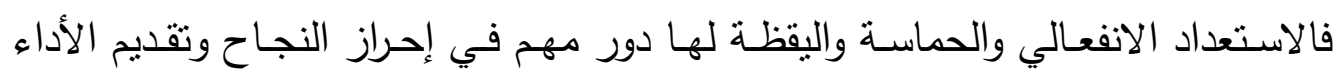

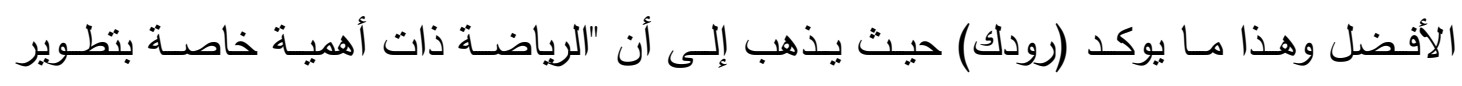

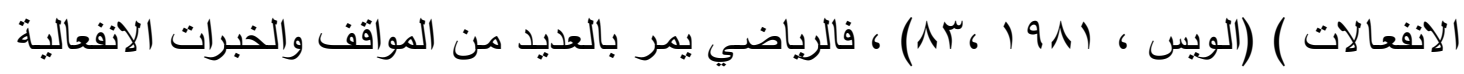
سواء ان كان ذلك في حالة التدريب او المنافسة الرياضية مما يتطلب من القائم بالعملية التدريبية جعل الناحية التدربيية ممتعة مع تأكيد التعاون القائم على التقة والاحترام المتبادلين بين الرياضي 
وجماعته سواء ان كان داخل الملعب او خارجه حيث أن التعاون والمنافسة الرياضية يسيران جنبا الى جنب مع النشاط الرياضي مما يساعد على خلق انفعالات جيدة ومن ثم تقديم الأداء الأفضل في المباريات الرياضية.

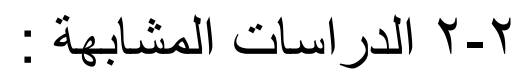

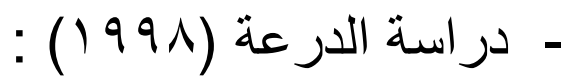

" علاقة مستوى الطموح ودافعية الإنجاز والاستجابة الانفعالية بنتائج مباريات كرة اليد" لآل هدف الباحث التعرف على : - مستوى الطموح وادفعيـة الانجاز والاستجابة الانفعالية للاعبي الدوري العام لكرة اليد بدولـة

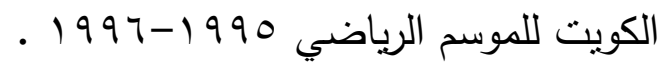

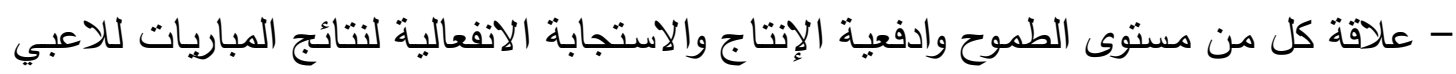

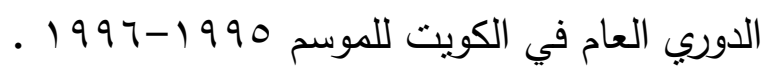
- العلاقة المتبادلة بين مستوى الطموح وادفعية الانجاز والاستجابة الانفعالية للاعبي الدوري

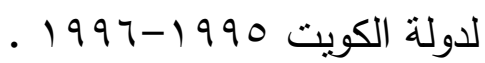
وقا وضع الباحث أريعة فروض : ا ـ توجد فروق ذات دالـة إحصائيا لمستوى الطمـوح للاعبي الدوري بين فرق المقدمـة وفرق

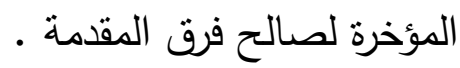

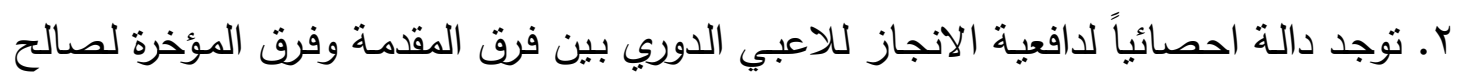

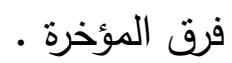
r. توجد دالـة إحصائيا للاستجابة الانفعاليـة للاعبي الدوري بين فرق المقدمة وفرق المؤخرة

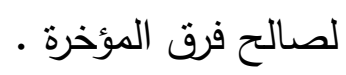
ع. توجد علاقة ايجابية دالة إحصائيا بين المتغيرات النفسية قيد الدراسة .

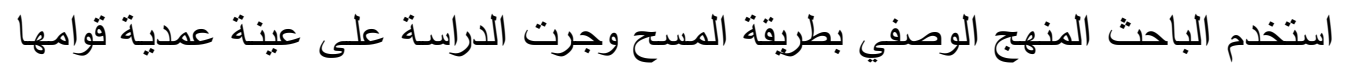
(91) لاعبا من لاعبي أندية الدرجة الأولى لكرة اليد للموسم الرياضي 1990 1997 199 وعددها

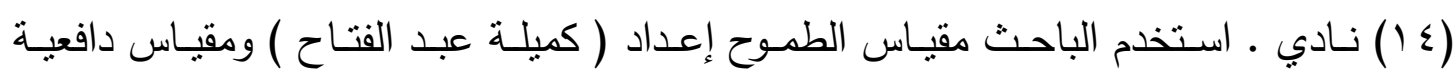
الانجاز إعداد ( إبراهيم قشقوش) ومقياس الاستجابة الانفعالية إعداد ( توماس تتكو ) واستخدم

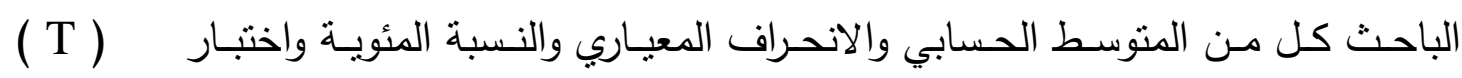

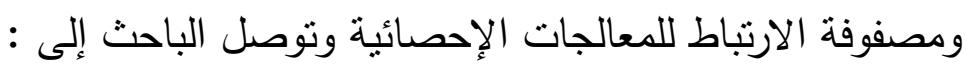
- مستوى الاستجابة الانفعالية عالية . 
- هنـاك ارتبـاط طـردي موجب ببين مستوى الطهوح وادفعيـة الانجـاز و الاسـتجابة الانفعاليـة

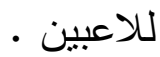

- توجد فروق دالة احصائياً في مستوى الطموح وادفعية الانجاز والاستجابة الانفعالية للاعبين

$$
\text { وأوصى بما يأتي: }
$$

* ضرورة تتمية المتغيرات النفسية قيد الدراسة للاعبي كرة البد واستثمارها لأجل الفوز • * إعداد برامج نفسية قبل فتزة المباريات لتهيئة النلاعبين . * أجراء دراسات مشابهة على لاعبي كرة اليد في المستويات المختلفة.

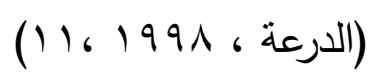

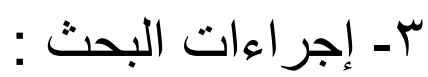

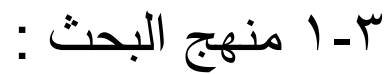

استخدم الباحث المنهج الوصفي بالطريقة المسحية لملاءمته وطبيعة المشكلة .

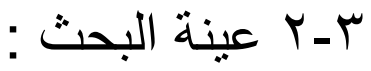

تم اختبار عينة البحث بالطريقة العمدية وتمنلت بلاعبي الوثب والرمي في فعالية العاب

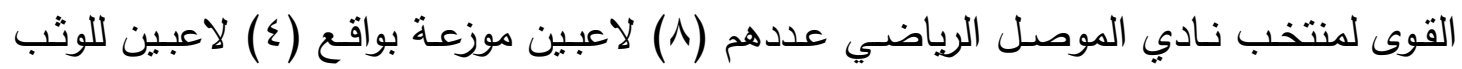

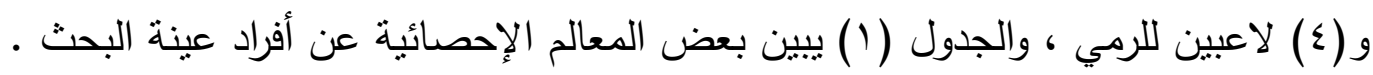

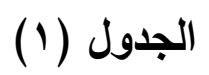

يبين المعالم الإحصائية للطول والوزن والعمر والعمر التدريبي لإفراد عينة البحث

\begin{tabular}{|c|c|c|c|c|}
\hline \multicolumn{2}{|c|}{ فعالية الرمي } & \multicolumn{2}{|c|}{ فعالية الوثب } & الفعاليات \\
\hline$\varepsilon$ & س & $\varepsilon$ & س & 5 \\
\hline., 990 & $1, \wedge \vee$ & $\cdot, .00$ & $1, v \leq$ & الطول / سم \\
\hline$r \cdot, r \varepsilon$ & $11, \ldots$ & $\varepsilon, 0 \leqslant$. & $v r, \ldots$ & الوزن / كفم \\
\hline$\cdot, \wedge 1$ & $r \leqslant, \ldots$ & $\cdot, \diamond \vee$. & $r r, O$. & العمر /سنة \\
\hline., 0 & r, r. & . & $0, \ldots$ & العمر التدريبي \\
\hline
\end{tabular}

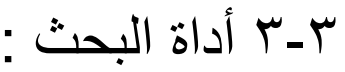

تم استخدام مقياس الاستجابة الانفعالية : الإن 
ب- - ا وصف المقياس وتصحيحه :

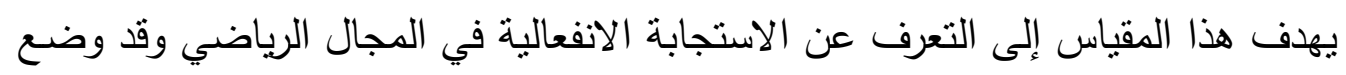

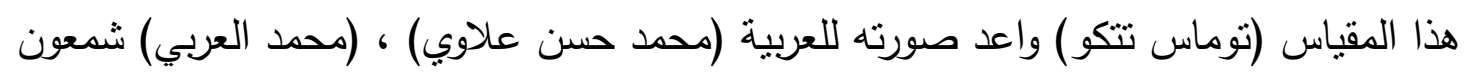

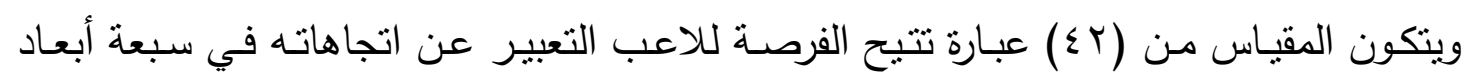

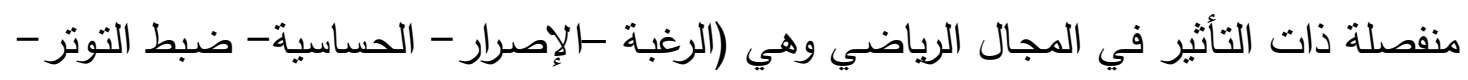

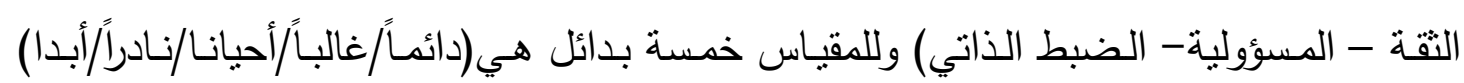
فضلا عن إعطاء (0-1) كوزن عبارة الايجابية وبالعكس (1-0) للعبارات السلبية ،وعليه يكون

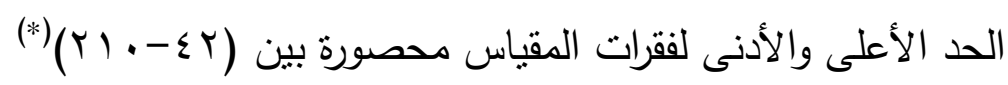

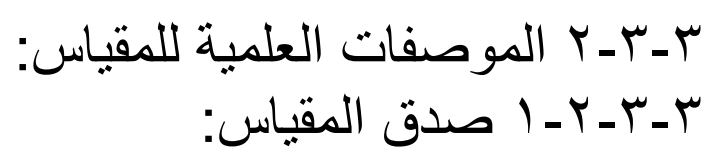
يعد صدق المقياس من أهم شروط الاختبار الجيد ، فالاختبار الصادق هو الذي ينجح

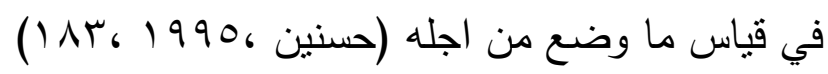

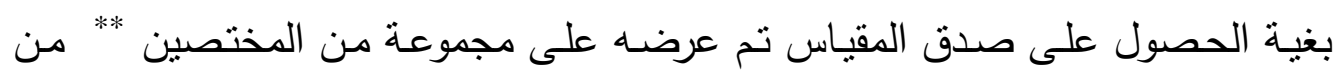

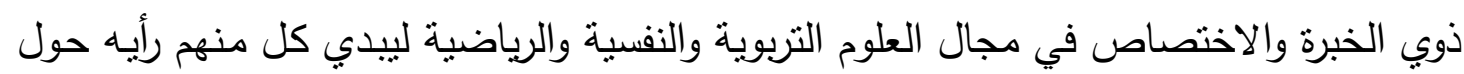

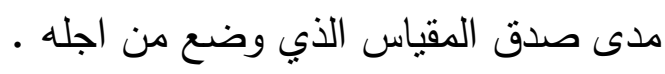

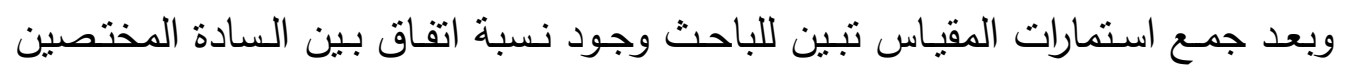

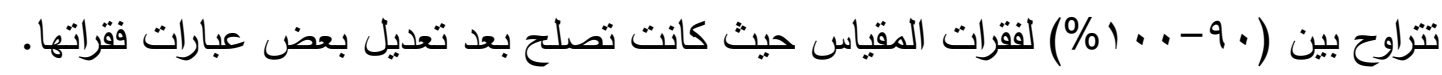

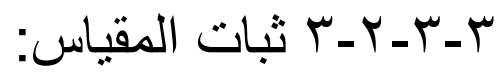

لغرض الحصول على ثبات المقياس تم توزيع استمارات المقياس على لاعبي منتخب

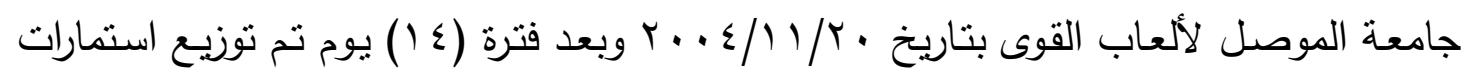

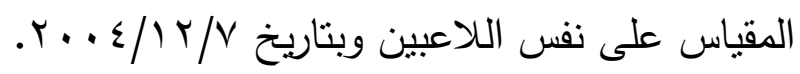

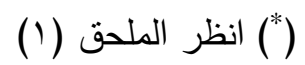

كلية التربية / قسم العلوم التزبوية والنفسية/جامعة الموصل

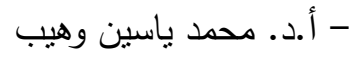

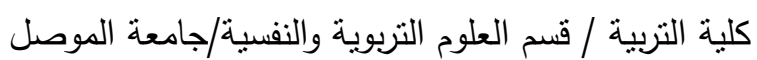
- أ. أ.د. كامل عبد الحميد عباس وهيب كلية التربية الرياضية/جامعة الموصل

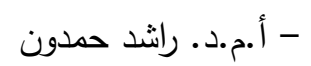

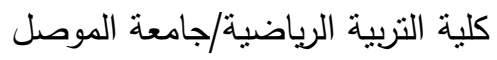

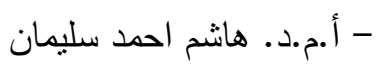

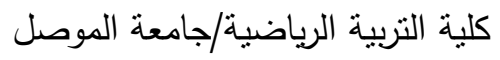

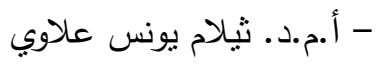




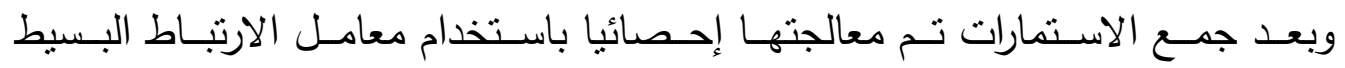
(بيرسون ) ظهرت قيمة (r) ( 9 ( ) ). وهذا يدل على وجود ارتباط عال ومن ثم وجود معامل ثبات عال للمقياس . ب-ع الأجهزة و الأدوات المستخدمة في البحث : شريط قياس ، ميزان طبي ، استمارات لمقياس الاستجابة الانفعالية .

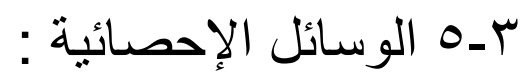

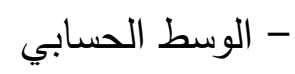

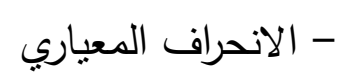

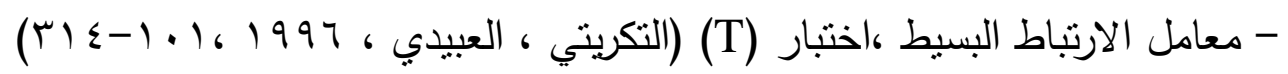

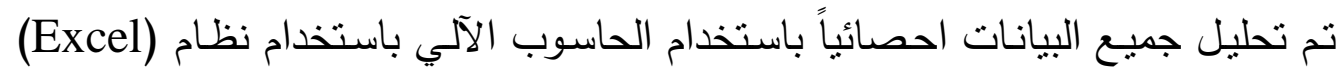
وتحت إثراف متخصص في هذا المجال .

\section{ع - عرض النتائج ومناقنتها :}

بغية تحقيق أهداف وفروض البحث وتوضيح الاسباب التي كانت وراءها وتفسير النتائج وبعد جمع البيانات ، فقد قام الباحث بمعالجتها بجداول إحصائية

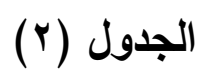

يبين المعالم الإحصائية لارجة الاستجابة الانفعالية لإفراد عينة البحث

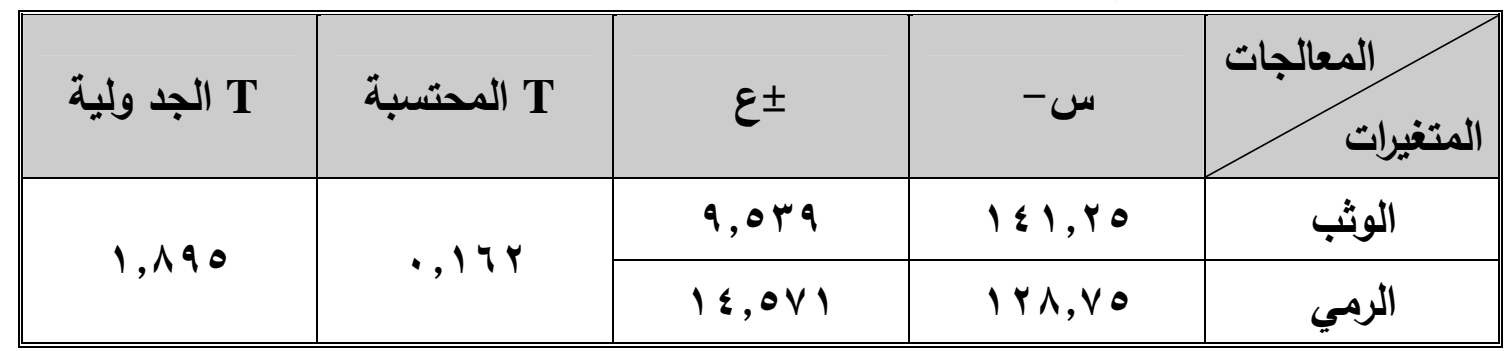

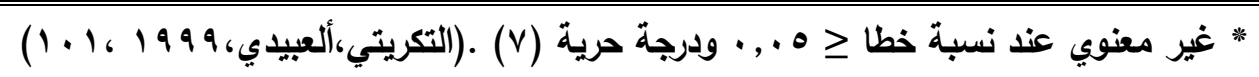

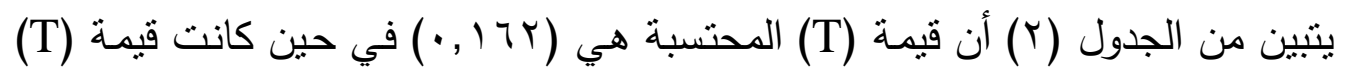

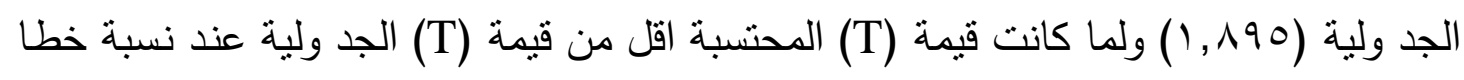

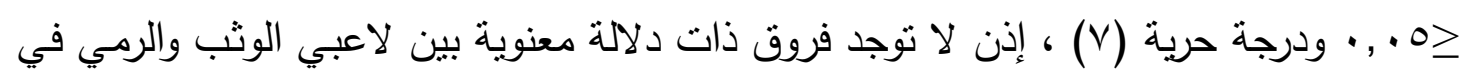
الاستجابة الانفعالية. 
الجدول (r)

يبين المعالم الإحصائية لكل بعد من الأبعاد السبعة في مقياس الاستجابة الانفعالية

\begin{tabular}{|c|c|c|c|c|c|}
\hline \multirow{2}{*}{$\begin{array}{c}\text { المحتسبة } \\
\text { المتبة }\end{array}$} & \multicolumn{2}{|c|}{ الرمي } & \multicolumn{2}{|c|}{ الوثب } & \multirow[t]{2}{*}{ المعالجات } \\
\hline & $\varepsilon \pm$ & 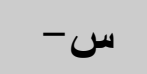 & $\varepsilon \pm$ & 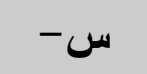 & \\
\hline$\cdot, \wedge r q$ & $\cdot, \wedge 17$ & iv & $1, \wedge 9 r$ & IV, ro & البعد الأول : الرغبة \\
\hline$\cdot$, ron & $r, 0$ & IV, ro & $1, V \cdot V$ & 19,10 & البعد الثاني: الإصرار \\
\hline$\cdot, \lambda r$. & $\cdot, \wedge 17$ & iv & $1, \wedge 9 r$ & IV, YO & البعد الثالث: الحساسية \\
\hline$\cdot, \varepsilon 1 \mu$ & $r, 9 \wedge 7$ & 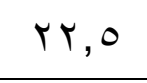 & $1, \varepsilon 1 \leqslant$ & r) & البعد الرابع: ضبط التوتر \\
\hline$\cdot, 1 \wedge V$ & $7, \cdot r V$ & 19,80 & $r, \cdot \wedge l$ & $r, 0$ & البعد الخامس: التثة \\
\hline$\cdot, M_{M}$ & $1,0 \mathrm{~V}$ & $r \cdot, 0$ & r,TrT & $r \leqslant, r_{O}$ & البعد السادس: المسؤولية الثخصية \\
\hline$\cdot, \ldots r$ & 1,0 & $1 \leqslant, V_{0}$ & $1, Y 01$ & $19, Y_{0}$ & البعد السابع:الضبط الذاتي \\
\hline
\end{tabular}

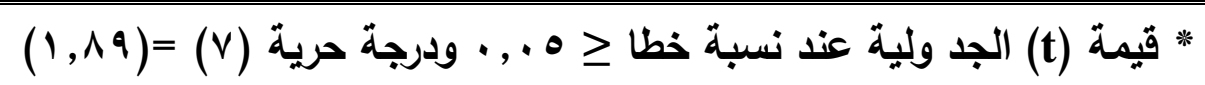

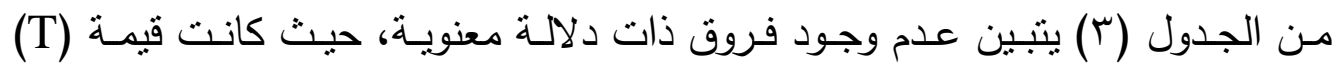

المحتسبة في جميع أبعاد المقياس اقل من قيمة (T) الجدولية والبالغة (19 , ( ) عند نسبة خطا

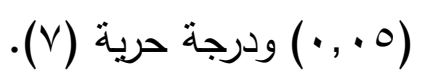

وعلى الرغم من عدم وجود فروق معنوية بين لاعبي الوثب ولاعبي الرمي في الاستجابة الانفعالية وأبعادها السبعة (الجدول (r) و (r)) إلا أننا نلاحظ في الجدول (r) ان هناك فروق في الأوساط الحسابية في الاستجابة الانفعالية وكذلك في الجدول (ץ) نلاحظ ان هناك فروق في الأوساط الحسابية في جميع أبعاد المقياس ما عدا في بعد ضبط التوتر ولصالح لاعبي الوثب. ويعزو الباحث هذه الحالة إلى أن العمر التدريبي للاعبي الوثب كان أطول من العمر التدريبي للاعبي الرمي ، وهذا قد يعكس لنا حالة من التكيف مع مواقف الاستجابة الانفعالية المختلفة ، حيث أن لاعبي الوثب قد تعرضوا لمواقف لعب مختلفة سواء في التدريب أو المنافسة ولفترة أطول من لاعبي الرمي . وهذا مااكده (حسين ونصيف • •91 (1) على انه : يمكن تطوير مستوى الرياضي من خلال التكريب المستمر وبعمر مبكر بحيث يتمكن من سرعة تعلم التكنيك والانسجام السريع عند تصعيب التدريب ،كما انه يتأقلم بسرعة على قابلية انسجام سريعة للصفات الوظيفية للحوافز 
والمؤثرات التي تعطى له من خلال التدريب المستمر طبقا لثروط الفعالية أو نوع اللعبة الممارسة بمـا في ذلـك أجهزة القلب والـدوران والجهـاز العصبي العضلي والمطاولـة النفسية (حسين ونصيف، (r)

" تلعب الخبرة التتافسية دورا كبيرا في تحديد الحالة الانفعالية للاعب فاللاعب المتقدم ذو

الخبرة التتافسية الجيدة يكون عادة اقل عرضـة للانفعـالات المختلفة من اللاعب الناشـى في المواقف المتشابهة .فالموقف الصعب بالنسبة للاعب الناثـى يمكن أن بعد موقفا عاديا بالنسبة للاعب المتقدم ويعرف (اولاتوفسكي) الخبرة التنافسية بأنها مجموع الخبرات والمعـارف التي يكتسبها اللاعب نتيجة لمشاركاته المتعددة في المنافسات المختلفة التي تمكنه من القدرة على مواجهة المواقف الصعبة في أثناء السباق وتتمي عنده روح التتافس وترفع من روحه المعنوية"

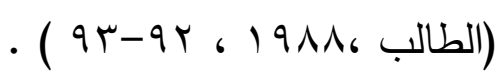

هذا ما يدعم النتائج التي نوصل إليها الباحث من أن العمر التدريبي (الخبرة التتافسية) لدى لاعبي الوثب في التدريب أو المنافسة كان أطول من العمر التدريبي للاعبي الرمي مها أدى إلى ظهور فروق في الاستجابة الانفعالية لصالح لاعبي الوثب حيث كلما زادت طول فترة التدريب أو كثرة المشاركات المحلية أو الدولية سوف نؤدي بدورها إلى رفع مستوى الاستجابة

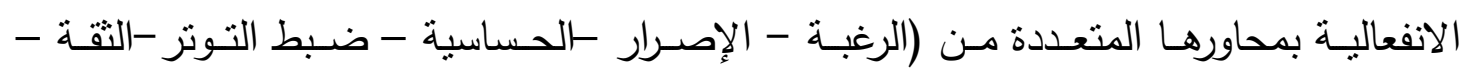
المسؤولية الثخصية - الضبط الذاتي ) ومن ثم رفع مستوى الإنجاز وحسب مواقف اللعب

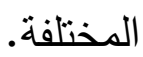


0 - الاستتناجات و التوصيات

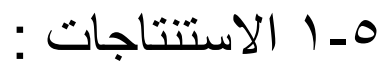

ا ـ هنالك تباين في الاستجابة الانفعالية بين لاعبي الوثب ولاعبي الرمي.

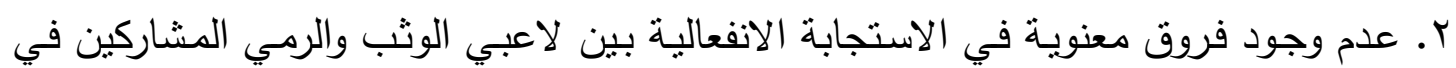

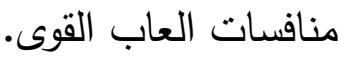

r. عدم وجود فروق معنويـة في كل بعد من الأبعاد السبعة للاستجابة الانفعالية بين لاعبي الوثب والرمي المشاركين في منافسات العاب القوى.

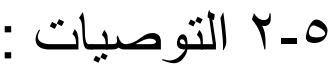

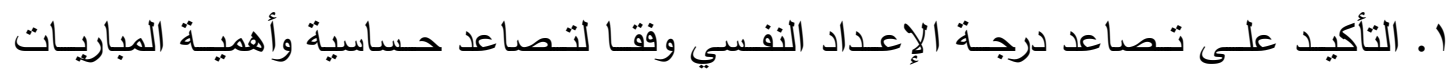
والمنافسات التي يخوضها اللاعبون.

r. يجب أن لا يكتفي الرياضي بتوفير الصفات النفسية المطورة لديه بل عليه ان بستحضر هذه وفه الصفات في أقصى الظروف قساوة وفي ظروف الصراع العنيف والتوتر ضد منافسين أقوياء.

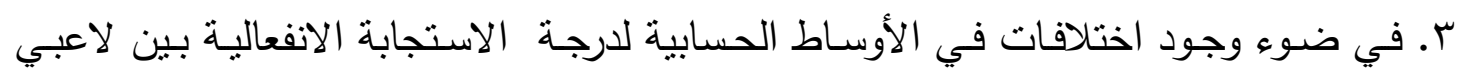

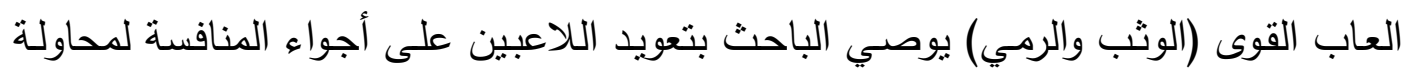
الوصول بالفرد الرياضي لدرجة مثالية الاستجابة الانفعالية لمواقف اللعب.

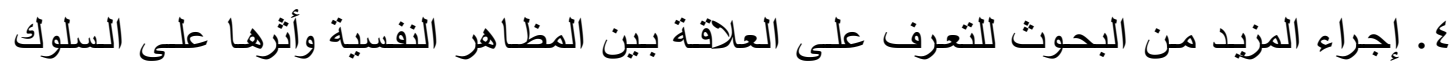

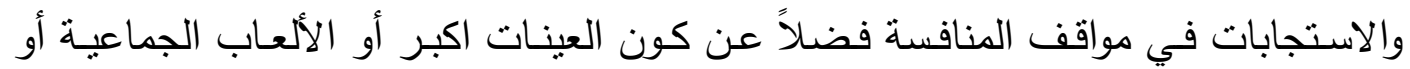

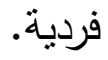


1. ارنوف ، وتتيج (9VV ( I ) : مقدمة في علم النفس (ترجمة) عادل عز الدين الاشول وآخرون ، دار ما كجروهيل للنشر ، مصر. r. التكريتي ، وديع ياسين والعبيدي ، حسن محمد (999 (19) التطبيقات الإحصائية في بحوث التربية الرياضية ، دار الكتب للطباعة والنشر ، الموصل. بالنين r. خان ، اميمة علي (·9VI) : علم النفس ، مطبعة العاني ، بغداد.

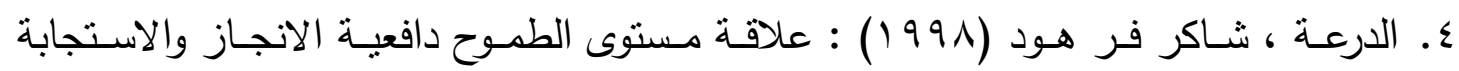
الانفعالية بنتائج مباريات كرة اليد ، المجلة العلمية للتربية البننية والرياضية ، كلية التربية بنات جامعة الإسكندرية. 0. راتب ، أسامة كامل (1990) : علم النفس الرياضة ،دار المعارف ، القاهرة.

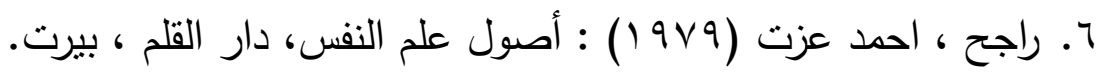

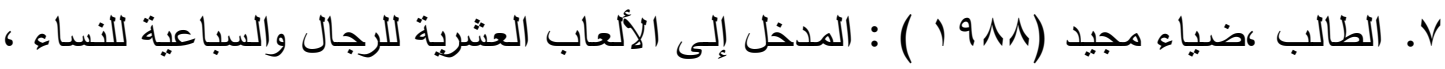
دار الكتب للطباعة والنشر ، الموصل.

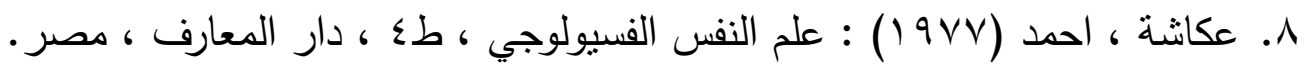

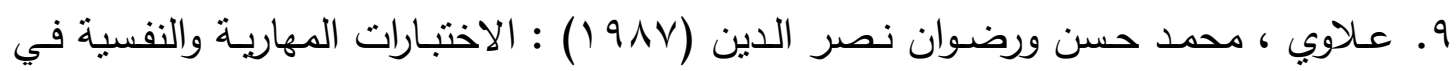
المجال الرياضي ، دار الفكر العربي ، القاهرة.

• (. علاوي ، محمد حسن (9V9 (1) : علم النفس الرياضي طـ؛، دار المعارف ، مصر. | ا. عيسوي ، عبد احمد محمد (910 (1) : علم النفس الفسيولوجي ، دار المعرفـة الجامعيـة، مصر

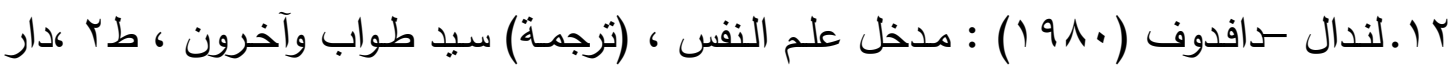

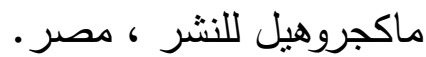

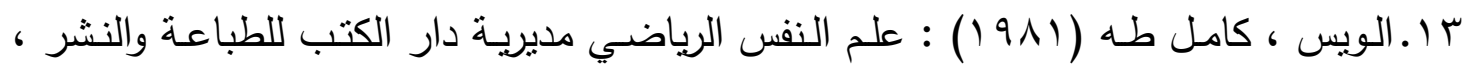

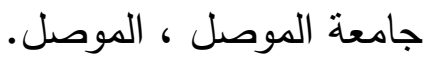

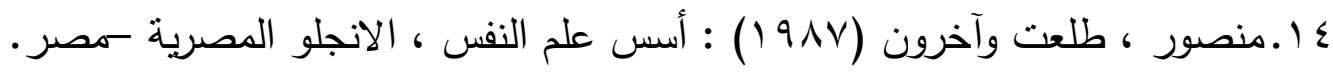
15. Hasset,James,Aprmer of Psychophysiology.U.S.A :W.H.Freeman and company, 1978. 
ملحق (1)

جامعة الموصل

كلية التربية الرياضية

م/صدق مقياس

نهديكم أطيب تحياتتا..........

يقوم الباحث بأجراء البحث الموسوم "دراسـة مقارنة في الاستجابة الانفعالية بين لاعبي

فعاليات الوثب والرمي بالعاب القوى " .

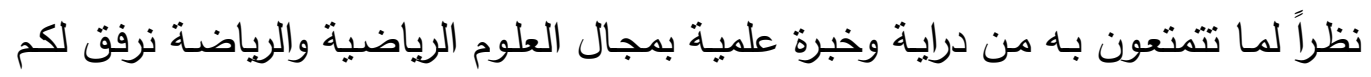

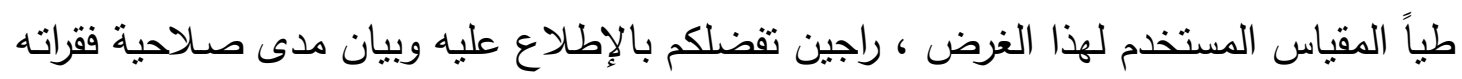

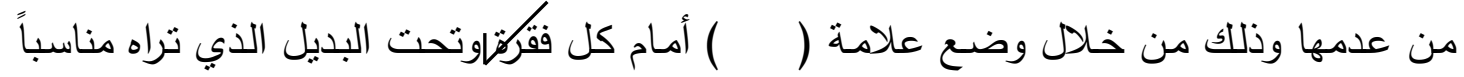

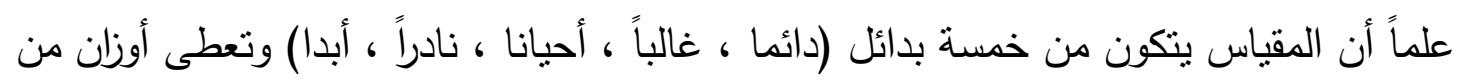
(0) (1) للعبارات الايجابية وعكسها للعبارات السلبية.

$$
\begin{aligned}
& \text { اسم الخبير : } \\
& \text { اللقب العلمي : } \\
& \text { الاختصاص : } \\
& \text { التاريخ : الإنيخ } \\
& \text { التوقيع : }
\end{aligned}
$$

الباحث

\section{rr.}

